Journal of Engineering and Applied Sciences 13 (18): 7729-7731, 2018

ISSN: 1816-949X

(C) Medwell Journals, 2018

\title{
The Effect of Post Cure on the Mechanical Properties of Chopped Fiber Reinforced Epoxy Laminate Matrix
}

\author{
Hisham Mohammed Ali Hasan \\ College of Computer Science and Information Technology, University of Al-Qadisiyah, \\ 58001 Diwaniyah, P.O. Box 88, Iraq
}

\begin{abstract}
This study presents the effect of cure and post-cure on mechanical properties of random chopped e-Glass, carbon fiber reinforced epoxy composites. At first, $2 \mathrm{~mm}$ fibers reinforced epoxy matrix of dog-bond specimens cure for $12 \mathrm{~h}$ at room temperature $25^{\circ} \mathrm{C}$ and post cure for $12 \mathrm{~h}$ at 50 and $100^{\circ} \mathrm{C}$ temperatures for all specimens a fragmentation tensile test where used, the strain energy release rate was calculated at cure and post cure temperatures, the strain energy release rate increase as post cure temperature increase.
\end{abstract}

Key words: Chopped fiber, e-Glass fiber, carbon fiber, epoxy matrix, fragmentation test, strain energy release rate

\section{INTRODUCTION}

Composites are generally used because they have desirable properties which could not be achieved by either of the constituent materials acting alone. The most common composite is the fibrous composite consisting of reinforcing fiber embedded in polymer matrix, short fiber reinforced thermoset polymer have several attractive characteristics that make them worthy of consideration such as in components having complex geometric contours and resin/short fibers can be easily injection or compression molded to produce parts having complex shapes (Gibson, 1994). Curing is an irreversible reaction where chemical covalent cross-links are formed which are thermally and mechanically stable. The curing process plays a major role in achieving the final mechanical properties and chemical resistance of the material (Kumar et al., 2015). State of epoxy polymer resin is liquid (soft) before the fabrication of composite which then changes to solid matrix (hard) after curing. Current investigation intends to study the effect of the post cure on the strength of composite fiber length on mechanical and thermos-mechanical properties of short e-Glass, carbon fibers composites, using $2 \mathrm{~mm}$ fibers length to reinforce an epoxy resin matrix. Mechanical properties were obtained by defragment tensile tests with dog-bond specimens, the produced plates were then subject to a cure and post cure processes. The cure was at room temperature, 50 and $100^{\circ} \mathrm{C}$. From defragment test the force $(\mathrm{kN})$ versus deformation $(\mathrm{mm})$ for each specimen and the strain energy can be derived for elastic and plastic deformation (Atkins and Mai, 2000; Tada et al., 2000) toughness energy values can be readily calculated from the load-deformation plot using numerical integration, integration was done by summing the area under the curve between successive load/deformation data points consecutively, a polygon quadrilateral with two parallel sides is a trapezoid (Petersen et al., 2006; Greenspan et al., 1986).

Where:

$$
\text { Area }=\sum \frac{1}{2}(\text { basic }+ \text { top })(\text { height })
$$

The toughness energy represented by the area under the curve would be including the stress failure, friction force effect and residual thermal stresses.

\section{MATERIALS AND METHODS}

Experimentation: A fiber length and diameter averaging of $3 \mathrm{~cm}$ and $10 \mu \mathrm{m}$, respectively were used as the reinforcement for short-fiber/epoxy and carbon/epoxy composite system. Dog-bond specimens of $40 \%$ fiber volume fraction with epoxy resin produced using steel moulds Fig. 1 and the specimens dimension as in Fig. 2. Dog bone tensile test samples are primarily used in tensile tests. Universal testing machine (maximum capacity $190 \mathrm{kN}$, crosshead speed $1 \mathrm{~mm} / \mathrm{min}$ ). The sample has a shoulder at each end and a gauge section in between. The shoulders are wider than the gauge section which causes a stress concentration to occur in the middle when the sample is loaded with a tensile force. This stress

Corresponding Author: Hisham Mohammed Ali Hasan, College of Computer Science and Information Technology, 


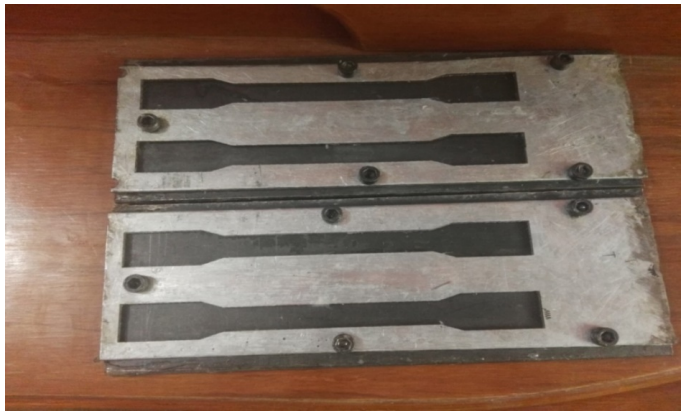

Fig. 1: Dog bond steel mold

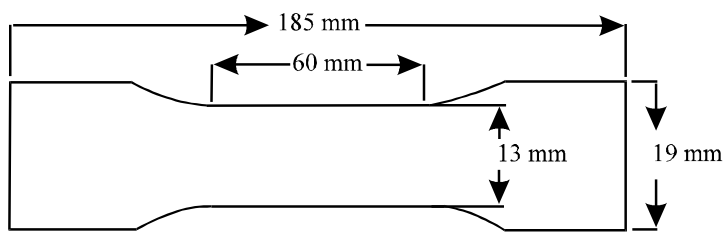

Fig. 2: Dimensions of dog-bond specimen (Anonymous, 2014)

concentration ensures a higher probability that the sample will rupture away from the ends. When the rupture of a sample occurs in the midsection it is attributed to the material reaching its maximum tensile strength whereas if the sample ruptures at one of the ends or in the grip itself the failure may be attributed to improper loading or a pre-existing defect in the material. The produced plates were then subject to a cure and post cure processes. The cure was at room temperature for $12 \mathrm{~h}$ in the mold and the post cure was carried out as follows: $50^{\circ} \mathrm{C}$ for $12 \mathrm{~h}, 100^{\circ} \mathrm{C}$ for $12 \mathrm{~h}$.

\section{RESULTS AND DISCUSSION}

The curves of the tensile load versus deformation were obtained, showing a nearly linear until final failure and clearly show that the specimens fail immediately at maximum load. The tensile strength was assumed as the value of peak load divided by cross section area. The correct energy $(U)$ for calculating the strain energy release rate for mode I is:

$$
\mathrm{U}=\frac{1}{2} \mathrm{P}_{\mathrm{Q}}\left(\mathrm{U}_{\mathrm{Q}}-\mathrm{U}_{\mathrm{i}}\right)
$$

Where:

$\mathrm{P}_{\mathrm{Q}} \quad=$ The peak load

$\mathrm{U}_{\mathrm{Q}}$ and $\mathrm{U}_{\mathrm{i}}=$ The displacements in the fragmentation tests

Toughness values $\left(\mathrm{G}_{\mathrm{ic}}\right)$ were calculated from the corrected energy, the strain energy release rate $\mathrm{G}_{\mathrm{ic}}\left(\mathrm{J} / \mathrm{m}^{2}\right)$ given by:

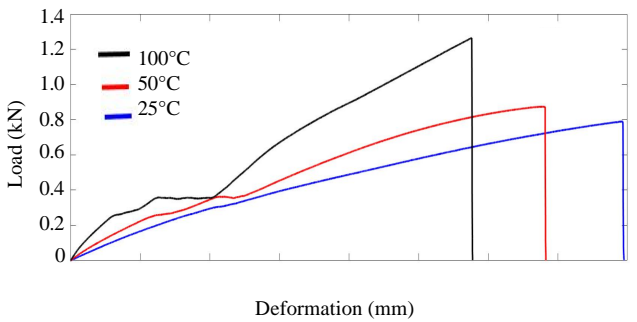

Fig. 3: Load-deformation curves for random e-Glass fiber reinforced epoxy matrix at post cure temperatures 25,50 and $100^{\circ} \mathrm{C}$

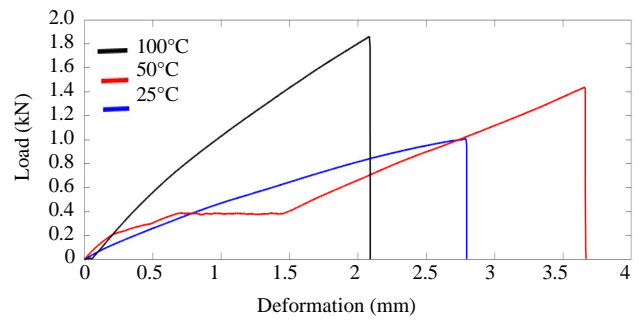

Fig. 4: Random-deformation curves for random carbon fiber reinforced epoxy matrix at post cure temperatures 25,50 and $100^{\circ} \mathrm{C}$

$$
\mathrm{G}_{\mathrm{ic}}=\frac{\mathrm{U}}{\mathrm{BW} \Phi}
$$

Where:

$\mathrm{B}=$ The specimen thickness

$\mathrm{W}=$ The specimen width

$\Phi=$ An energy calculation factor calculated from the ratio of crack length to coupon width

The correct energy represented by the area under curve have been calculated by numerical integration of the values which are tabulated from each force displacement curves (Fig. 3 and 4). In continuous fibers (the specimen were assumed to be perfectly embedded in an aligned arrangement) the orientation of fiber with respect of load direction plays an important role in determining the fracture toughness tensile load as the crack propagate through matrix and fiber when the direction of fiber is perpendicular with applied force or the crack propagate through the matrix only when the applied load is in direction of align fibers. In random orientation of chopped fiber reinforced epoxy matrix the applied force in parallel fiber direction will be less probable than other applied force-fiber directions. The strain energy release rate for each post cure temperature calculated by Eq. 3 and the tabulated values in Table 1, shown in Fig. 5. The temperature applied during the cure process would effected the chemical reactions in the resin which cause the desired changes in the molecular structure by 
Table 1: Strain energy release rate for e-Glass fiber reinforced epoxy and carbon fiber reinforced epoxy at post cure temperatures $25,50,100$ ${ }^{\circ} \mathrm{C}$

\begin{tabular}{lccc}
\hline $\begin{array}{c}\text { Post cure } \\
\text { temperature }{ }^{\circ} \mathrm{C}\end{array}$ & $\begin{array}{c}\text { Post cure } \\
\text { time }(\mathrm{h})\end{array}$ & $\begin{array}{c}\mathrm{G}_{\mathrm{ic}} \text { for e-Glass } \\
\text { fiber reinforced } \\
\text { epoxy }(\mathrm{kN} / \mathrm{mm})\end{array}$ & $\begin{array}{c}\mathrm{G}_{\mathrm{ic}} \text { for carbon } \\
\text { fiber reinforced } \\
\text { epoxy }(\mathrm{kN} / \mathrm{mm})\end{array}$ \\
\hline 25 & 12 & 0.013435 & 0.014560 \\
50 & 12 & 0.014133 & 0.016346 \\
100 & 12 & 0.015410 & 0.019134 \\
\hline
\end{tabular}

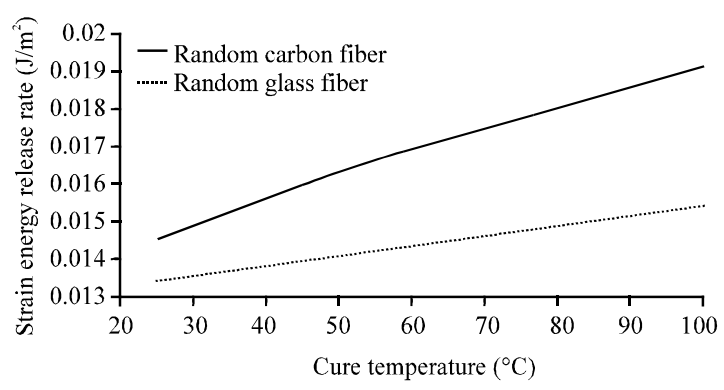

Fig. 5: The strain energy release rate-cure temperature for random e-Glass fiber, random carbon fiber reinforced epoxy matrix

increasing the cross linking and also effected the thermal stresses were the matrix resin and its reinforcement usually do not have the same thermal expansion coefficients.

\section{CONCLUSION}

The mechanical properties of chopped random orientation fiber reinforced epoxy matrix was affected by cure temperature by increasing the strain energy release rate as the post cure temperature increase for chopped e-Glass fiber and carbon fiber reinforced epoxy matrix the epoxy matrix do not fully cure at room temperature and as heat increase the cross-linking increase in the epoxy reaction (Hasan and Ismaeel, 2017). From the present investigation it was observed that post curing at $100^{\circ} \mathrm{C}$ for $12 \mathrm{~h}$ gave better thermal and mechanical properties as compared to post curing at different temperatures.

\section{REFERENCES}

Anonymous, 2014. Standard test method for tensile properties of plastics. ASTM D638-14, ASTM International, West Conshohocken, Pennsylvania. https://www.astm.org/Standards/D638.htm

Atkins, A.G. and Y.W. Mai, 2000. Propagation and Arrest of Joints and other Fractures. John Wiley \& Sons, Hoboken, New Jersey, USA.,

Gibson, R.F., 1994. Series in Mechanical Engineering. McGraw-Hill Education, New York, USA.,

Greenspan, H.P., D.J. Benney and J.E. Turner, 1986. Calculus. 2nd Edn., McGraw-Hill Education, New York, USA.,.

Hasan, H.M.A. and Z.M. Ismaeel, 2017. The effect of fiber direction on the adhesion strength and energy release rate in epoxy composite using defragment test. Res. J. Appl. Sci., 13: 328-331.

Kumar, D.S., M.J. Shukla, K.K. Mahato, D.K. Rathore and R.K. Prusty et al., 2015. Effect of post-curing on thermal and mechanical behavior of GFRP composites. Proceedings of the 4th National Conference on Processing and Characterization of Materials Vol. 75, December 5-6, 2014, IOP Publishing, Rourkela, India, pp: 012012-1-012012-6.

Petersen, R.C., J.E. Lemons and M.S. McCracken, 2006. Stress-transfer micromechanics for fiber length with a photocure vinyl ester composite. Polym. Compos., 27: 153-169.

Tada, H., P.C. Paris and G.R. Irwin, 2000. The Stress Analysis of Cracks Handbook. 3rd Edn., ASME Press, New York, USA., ISBN:9780791801536, Pages: 677. 